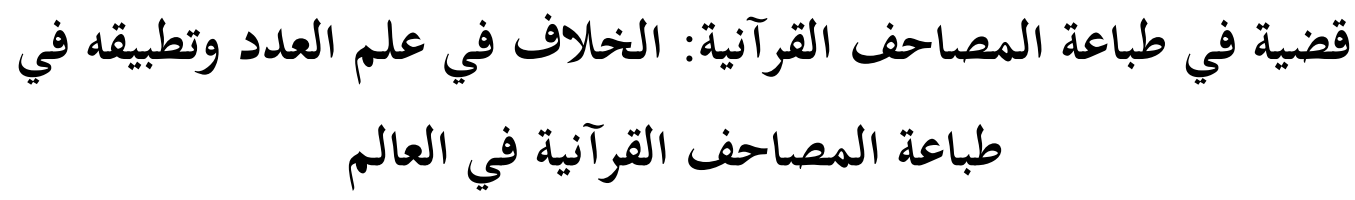

\title{
Issue in Printing Mushaf Quran: Dispute in Science of 'Adad and It's Application in Printing Mushaf Quran
}

\author{
ABD MUHAIMIN AHMAD*, SABRI MOHAMAD \& HAZIYAH HUSSIN ${ }^{1}$
}

\begin{abstract}
The science of 'adad constitutes an integral part of Quranic-affiliated knowledge. Its main discussion is about the beginning and ending of the verse of the Quran as well as distinction numbering of the verses. There are seven famous opinions in 'adad, namely; Madani Awwal, Madani Akhir, Makki, Kufi, Basri, Shami and Himshi. The difference of opinions in the determination of Quranic verses does not only affect the calculation of the total number of verses in the Qur'an, but also contribute to the differences in the nature of mushaf (printed Quran). This is because the scholars have variant views on determining the madhdhab (opinion) of 'adad relied upon by some qiraat mutawatirah and its riwayah. Thus, this study explores and gathers the views of the scholars in determining the madhdhab (opinion) for respective qiraat mutawatirah, and identify their justifications. This study will then examine the effect of the dispute on mushaf Quran. To achieve the aforementioned objectives, content analysis method was adopted to bring together the views of scholars in determining opinions for each qiraat mutawatirah, and to analyze descriptively the narrations of all opinions to explain the cause of the disagreement among the scholars. In order to know the impact of the differences in 'adad on mushaf Quran, induction methods was used on the mushaf Quran which has been printed in several countries with distinctive qiraat mutawatirah. This study finds that the sanad (chain of transmitter) in narrating 'adad forms is the contributing factor in dissenting scholars in determining credible opinion for each qiraat mutawatirah. In regards to the printing of mushaf, most of the printed mushafs are aligned with the opinion of scholars in determining the number of the verses, whereas only a few of mushaf which do not comply with such opinion.
\end{abstract}

Keywords: al-`adad, al-Quran numbering, mushaf, qira'at

\footnotetext{
1 Abd Muhaimin Ahmad*(Corresponding author), Ph.D. candidate at Dept. of al-Quran and al-Sunnah Studies, Faculty of Islamic Studies, Universiti Kebangsaan Malaysia, 43600 BANGI, Selangor, Malaysia, email: muhaimin@usim.edu.my; Sabri Mohamad, Ph.D., Senior Lecturer at Dept. of al-Quran and al-Sunnah Studies, Faculty of Islamic Studies, Universiti Kebangsaan Malaysia, 43600 BANGI, Selangor, Malaysia, email: sabri_mohamad@ukm.edu.my; Haziyah Hussin, Ph.D., Senior Lecturer at Dept. of al-Quran and al-Sunnah Studies, Faculty of Islamic Studies, Universiti Kebangsaan Malaysia, 43600 BANGI, Selangor, Malaysia, email: haziyah@ukm.edu.my.
} 
فإن المسلمين في جميع أنحاء العالم يقرؤون القرآن الكريم بعدة روايات متواترة مختلفة، وأغلبهم يقرؤون بقراءة عاصم من رواية حفص الكوفي. وبجانب هذه الرواية، هناك روايات أخرى قرأ بها المسلمون في بعض الدول

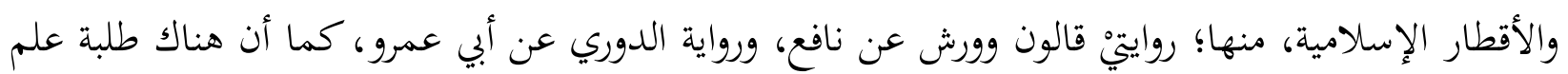

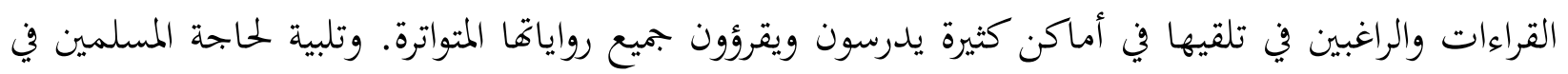

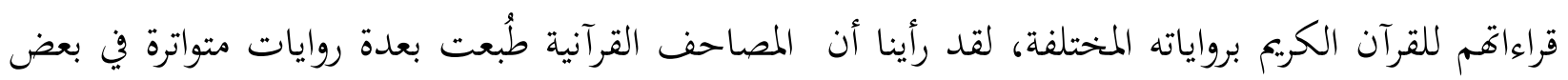
الدول الإسلامية. ومما لاحظنا في شأن هذه المصاحف، وجود اختلافات يسيرة في عدد آياتما -جملة وتفصيلاً-حسب العدد المعتمد لكل القراءات والروايات. وقد نوقش هذا الخلاف في علم ما سمّي بعلم العدد أو علم الفواصل. والمتتبع لهذا العلم، يجد أن علماء العدد والقراء اختلفوا في اعتبار مذهب العدد لبعض

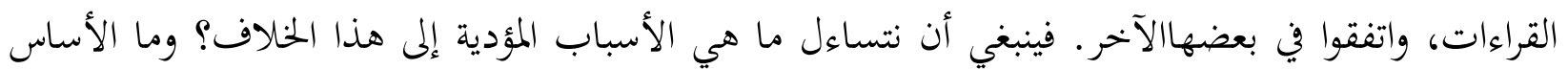
الذي بنى عليه العلماء في اعتبار مذاهب العدد لجميع القراءات؟ وهل المصاحف القرآنية التي طبعت على اختلاف رواياةًا تطابق ما قره علماء العدد؟

ولإجابة هذه التساؤلات، قام الباحثون بجمع النصوص المتعلقة بأسانيد مذاهب العدد من كتب العدد والقراءات، وقاموا بتحليلها لمعرفة العلاقة بين هذه الأسانيد، وخلاف العلماء في اعتبار مذهب العدد للقراءات. ثم قام الباحثون بجمعالمعلومات عن العدد المعول عليه في المصاحف المطبوعة لمعرفة مدى اعتماد المطابع مقارنةبما قرره علماء العدد.وقد جعل الباحثون لهذه الدراسة ثلاثة مطالب، وهي؛ التعريف بعلم العدد ومذاهبه، وأقوالالعلماء في تعيين مذاهب العدد للقراءات المتواترة ورواياها، والمصاحف القرآنية المطبوعة والعدد المعول فيها،واختتمها بخلاصة ونتائجالدراسة.

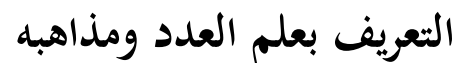

العدد لغة: إحصاء الشيء، يقال: عَلَّه يعده: أي أحصاه. والعدد: مقدار ما يعد ومبلغه(Ibn Manzur 2005). وفي الاصطلاح، لقد عرفه عبد الفتاح القاضي (2008) في شرح القصيدة ناظمة الزهر: "فهو فن بيحث فيه عن سور القرآن وآياته من حيث بيان عدد آي كل سورة ورأس كل آية ومبدئها". ولعبد الرازق علي إبراهيم (1989). تعريف آخر ما يشبه تعريف القاضي حين يشرح قصيدة الفرائد الحسان للقاضي، فيقول: "هو علم 
يبحث فيه عن أحوال آيات القرآن الكريم من حيث عدد الآيات في كل سورة، وما هي رأس الآية وما خاتمتها". وقال أحمد خالد شكري (2012): "هو العلم بأعداد آي سور القرآن وما اختلف في عده عده منها معزواً

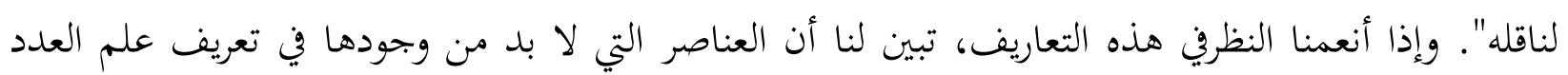
هي؛ معرفة عدد الآيات في سور القرآن ، ومواضع الخلاف في عد الآيات وتركها، ونسبة كل خلاف في الأعداد إلى ناقله.

\section{مذاهب العددالسبعة}

وقد جرت عادة علماء العدد على نسبة الأعداد إلى الأمصار؛ لا إلى الأشخاص، واختلفوا في رواية مذاهب العدد في كتبهم، فمنهم من اعتبر هذه المذاهب ستة، موافقة لعدد المصاحف الموجهة بها إلى الأمصار. فعلى إلى هذا كان لأهل المدينة عددان؛ المدني الأول، والمدني الأخير، وواحد لأهل مكة، وواحد لأهل الشام، وواحد لأهل الكوفة، وواحد لأهل البصرة(Abd al-Raziq 1989) . . وهذا اختيار الداني (1994) في كتابه "البيان" وتبعه في ذلك الشاطبي (al-Qadi 1997)، والسخاوي (1990)، والمخللاتي (1992).ومنهم من اعتبرها سبعة بزيادة عدد الحمصي على المذاهب الستة السالفة الذكر. وهذا اختيار الهذلي (2007) في "الكامل" -مع تشذيذه عدد وله الحمصي - والجعبري (2005) في كتابه "حسن المدد في العدد"، وتبعهما في ذلك الدمياطي (2006)، ومحمد بن علي الحداد (1924)، والمتولي، وعبد الفتاح القاضي (1984)، وعبد الرازق علي إبراهيم (1988). وبناء على هذا الاختيار، تكون الأعداد المرويةالمشهورة المتداولة بين علماء هذا العلم سبعة. لماحئ ومعظم الكتب التي روت هذه الأعداد -قديمها وحديثها- يدور إسنادها حول الأسانيد التي حواها كتاب "البيان" للداني. ومما يُلاحَظ في هذا الأمر،أن هذه الكتب استعملت عبارة متكررة وهي: "ما رواه

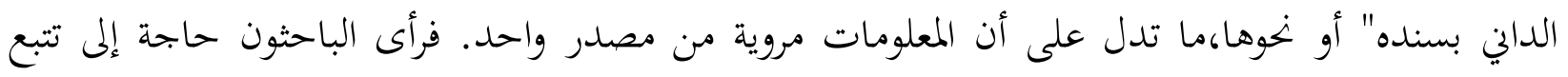

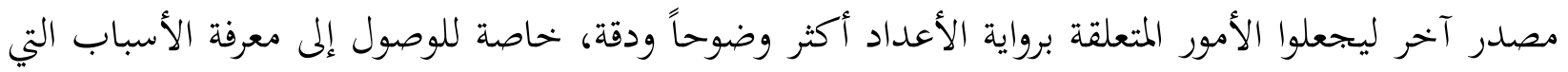
تسبب بهاالخلاف بين علماء العدد والقراءات في اعتبار مذهب العدد للقراءات المتواترة.ووجد الباحثون أسانيد أخرى لهذه الأعداد من كتاب "الكامل" للهذلي، ومعوها وقارنوها لتقوية رواية الأعداد في هذه الكتب بعضها بعضاً، وهي على النحو التالي:

https://doi.org/10.24035/ijit.8.2015.010 
• الأولى: العدد المادني الأول: هو الذي رواه نافع عن شيخيه أبي جعفر يزيد بن القعقاع وشيبة بن

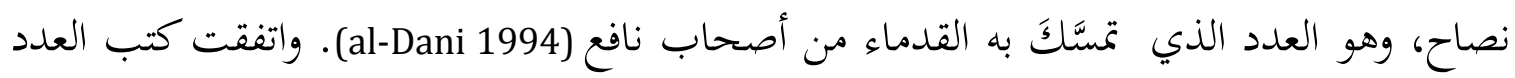
على أن هذا العدد رواه أهل الكوفة، ولم ينسبوه إلى أحد منهم بعينه، بل أوقفوه على جماعتهم .(al-Mukhallilati 1992; al-Haddad 1924; al-Qadi 1983; `Abd al-Raziq 1988) • ولكنها اختلفت في رواية أهل مصر وأهل البصرة لمذا العدد، حيث ذكر الداني -كما في النص النص السابق - أنه رواه أيضاً عامة المصريين عن عثمان بن سعيد ورش، ودونوه وأخذوا به (al-Dani 1994).

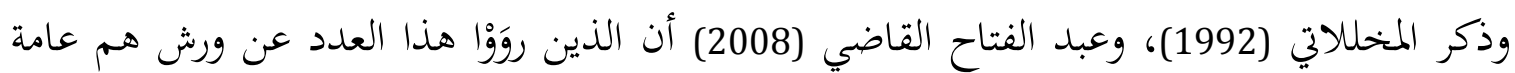
البصريين. وذكر الهذلي(2007 109) أن هذا العدد منسوب إلى أبي جعفر، ورفعه إلى رسول الله صلى اللى الله عليه وسلم من طريق ابن عباس عن أبي بن كعب رضي الله عنهم.

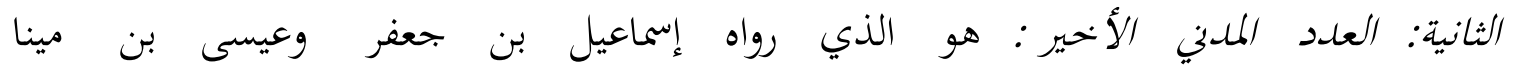

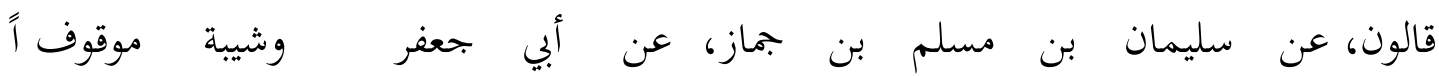

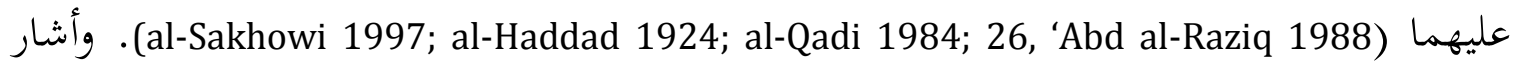
الهذلي (2007) أن هذا العدد منسوب إلى إسماعيل، ورفعهإلى رسول الله صلى الله عليه وسلم من طريق ابن عباس عن أبي بن كعب رضي الله عنهم. الثالثة: العدد المككي:هو الذي رواه عبد الله ابن كثير عن بحاهد بن جبن ربر عن ابن عباس عن أبي بن

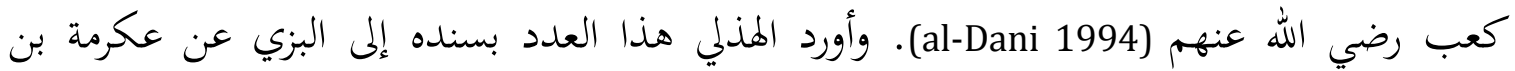
سليمان عن القسط عن عبد الله ابن كثير عن بحاهد (al-Huzali 2007).

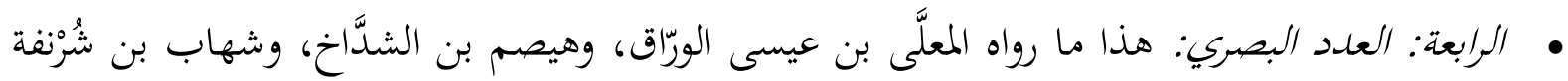

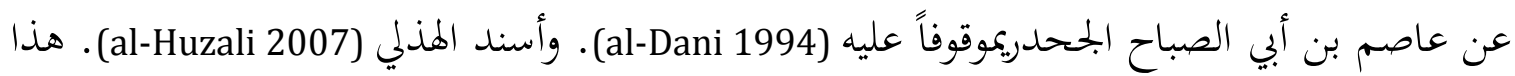
العدد إلى عمر رضي الله عنه فقال: "وأما عدد أهل البصرة فحدثنا أبو محمد عبد الله بن محمد بن الهن

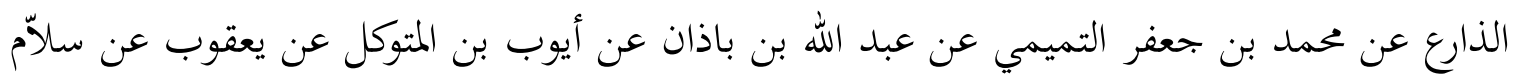

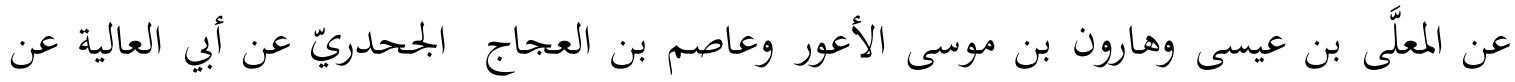


• الخامسة: علدد الكوفي: وهو ما رواه الداني بطريقتين؛ الأُوْلَى: ما أسند إلى سليم عن حمزة، عن أبي

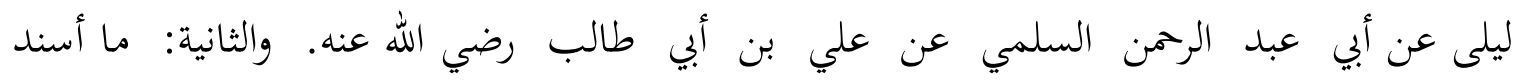

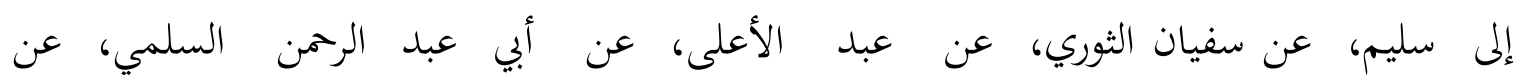

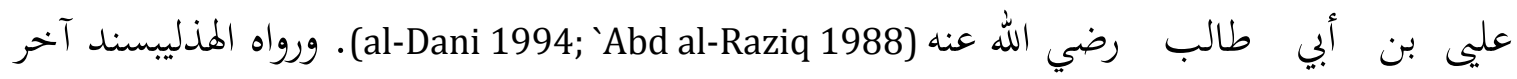

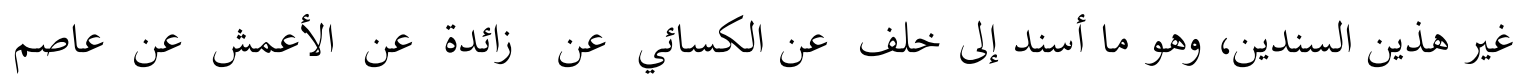
عن أبي عبد الرحمن عن علي رضي الله عنه (al-Huzali 2007). • السادسة: علدالشامي: وهو ما رواه الداني بسنده إلى أيوب بن تميم القارئ عن يهي بن الحارث

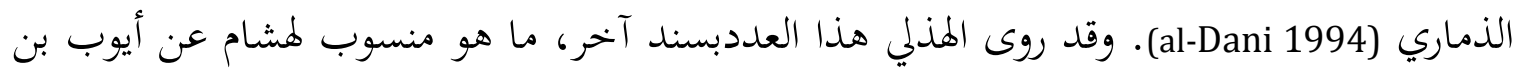
تميم عن يحي الذماري عن عبد الله بن عامر عن المغيرة بن شهاب المخزومي عن عثمان بن عفان رضي الله عنه (al-Huzali 2007).

• السابعة: علد الحمصي: وقد أشار الداني إلى هذا المذهب في كتابه رغماً أن هذا العدد لم يكن مختاراً

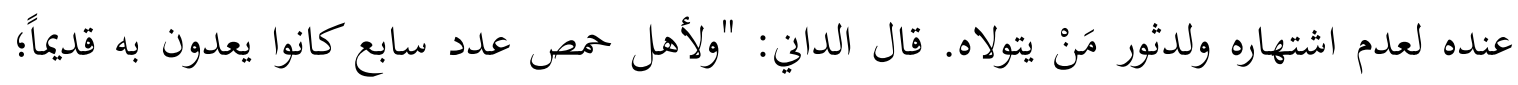
وافقوا في بعضه أهل دمشق وخحالفوهم في بعضه، وأوقفته جماعتهم على خالد بن معدان -رمحه الله-

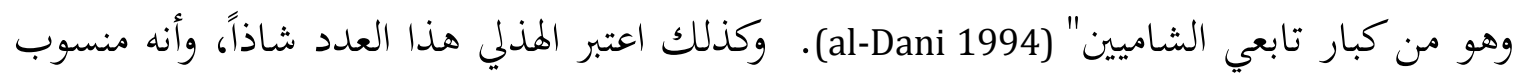
إلى ابن شنبوذ عن خالد بن معدان عن يزيد بن قطيب.(al-Huzali 2007).

\section{أقوال العلماء في تعيين مذاهب العدد للقراءات المتواترة ورواياتها}

رأى بعض العلماء -منهم عبد الرازق علي إبراهيم موسى ومؤلفو كتاب مقدمات في علم القراءات- أن كتابة وطباعة المصاحف القرآنية للقراءات العشر أو أحد رواية من رواياتا، لا بد رأد أن توافق العدد المشهور في بلدانها (Abd al-Raziq 1988; Ahmad Muhammad al-Qudah et al. 2009). قال عبد الرازق علي إبراهيم (1988): "نافع المدني أو راوييه يعتمد المدني الثاني...وأبو جعفر المدني يعتمد عدد المدني الأول، وابن

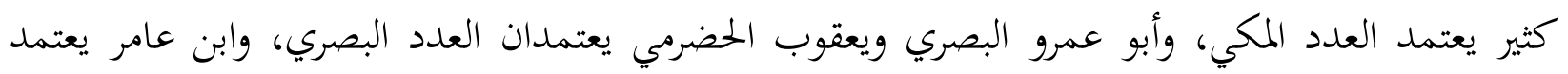
العدد الشامي". وذكر في كتاب مقدمات في علم القراءات: "وقد جرى اعتماد القراء في العدّ على العدد 
المشهور في بلداهم، ففي قراءة نافع يعتمد العدد المدني الأخير، وفي قراءة أبي عمرو يعتمد العدد البصري، وفي قراءة الكوفيين يعتمد العدد الكوفي" (Ahmad Muhammad al-Qudah et al. 2009). لكن الأمر يحتاج إلى تفصيل، إذ إن بعض الأمصار فيها مذهبان في العدد، وذلك،مثل: المدينة حيث

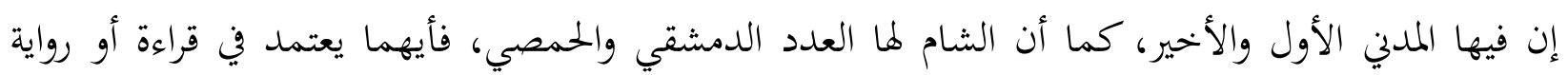

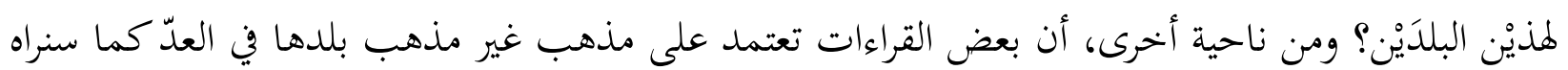
في التفصيلات فيما سيأتي ذكره.

والمدققفي هذه القضية، يجد أن العلماء اختلفوا في اعتبار مذهب العدد لبعض القراءات ورواياتا، كما أفم اتفقوا على البعض الآخر. وحسب اطلاع الباحثين المتواضع على بعض كتب العدد والقراءات، وجدوا أن اعتماد القراءات العشر ورواياتما في العدّ يمكن أن يقسم إلى قسمين على النحو التالي:

القسم الأول: ما اختلف فيه العلماء في اعتبار مذهب العدد له. وهو قراءة نافعوأبي عمر والبصري، وتفصيلا تعن مذهبهما في العدد على النحو الآتي: • قراءة نافع الملدي: اختلف العلماء في اعتبار مذهب العدد لهذه القراءة، فذهب بعضهم إلى إلى أها تعتبر المدني الأخير، وهو قولاملالقي(2003)، وابن الجزري (2006)، وتبعهما في ذلك الضباع (2002)، والقاضي (1983). ورأى فريق آخر بأغها المدني الأول، وهو قول الداني والمعبري (al-Safaqasi 1999 .(al-Dani 1994; • قراءة أبي عمرو البصري: وقد وقع الخلاف بين علماء العدد والقراءات في اعتبار مذهب العدد لقراءة أبي عمرو، حيث اعتبر بعضهم أها عدد بلده -البصري-، وهو قول قول المالقي (2003)، وابن الجزري (2006)، وتبعهما في ذلك الضباع (2002)، والقاضي (1983)، وعبد الرازق علي إبراهيم (1988). واعتبرها البعض الآخر عدد المدي الأول، وهو قول الداني (1994)، وتبعه في ذلك الجعبري (2005)، والنويري (2009)، والدمياطي (2006) احتجاجاً بعرض أبي عمرو على أبي جعفر المدني.

القسم الثاني: ما اتفق فيه علماء في اعتبار مذهب العدد له. وهو كل القراءات العشر المتواترة ما عدا قراءة نافع المدني وأبي عمرو البصري، والتفصيلا تعنها على نحو ما يأتي: 
• قراءة ابن كثير المكي: تعتبر قراءة ابن كثير عدد المكي في عد آياتا، ولا خلاف في ذلك بين علماء القراءات والفواصل. (al-Safaqasi 1999; ‘Abd al-Raziq 1988) ولا ينازع في ذلك أحد إذ إن سند هذا العدد يتصل مباشرة بهذا الإمام الجليل الذي تستند إليه هذه القراءة. • قراءة ابن عامر الشامي: كان لأهل الشام عددان -وهما العدد الشامي والحمصي-، وعلى الرغم من هذا، فإن علماء العدد والقراءات لم يختلفوا في اعتبار مذهب العدد لقراءة ابن عامر، حيث إفم اعتبروها عدد الشامي (al-Safaqasi 1999; ‘Abd al-Raziq 1988). ولا ريب في هذا إذ هذا العدد منسوب إلى هذا الإمام الجليل الذي تلقاه عن جماعة من الصحابة رضي الله عنهم. • قواءة الكوفيين الأببع -وهي قراءة عاصم وحزة والكسائي وخلف. لم يختلف العلماء في اعتبار العدد لهذه القراءات، فهم يعتبروها عدد الكووي المنسوب إلى أبي عبد الرحمن السلمي (Abd al-Raziq 1988; Ahmad Muhammad al-Qudah et al. 2009)، الذي تلقاه عن علي بن أبي طالب رضي الله عنه. وذلك لأن كل قراءات الكوفيين الأربع سندها يتصل بهذا التابعي الجليل الذي أرسله عثمان رضي الله عنه إلى الكوفة ليعلّم أهلها القرآن. • قراءة أبي جعغر الملني : اتفق العلماء على أن قراءة أبي جعفر تتبع المدني الأول في العد (al-Dani 1994; 'Abd al-Raziq 1988). وقد أسند الداني هذا العدد إلى أبي جعفر نفسه وشيبة -كما تقدم ذكره، وهذا يشير إلى أنه عدّ بهذا العدد. وقد أورد ابن مهران (2004) في ذكره لأسانيد قراءة أبي جعفر كلام أحمد بن محمد بن حنبل حين سأله رجل: "يا أبا عبد الله، بأي حرف ترى لي أن أقرأ؟ قال: حرف المدني الأول، قال: فإن لم أجد؟؛ قال: فبحرف عاصم." فهذه الحكاية تؤكد ما نقله العلماء بأن قراءة أبي جعفر تعتمد على المدلي الأول. قراءة يعقوب الحضومي: على الرغم من اختلاف العلماء في اعتبار العدد لقراءة أبي عمرو، فإننا لم بحد خلافهم في اعتبار بصرية قراءة يعقوب في العدد. قال الداني في بيان منْ عَدَّ بعدد البصري: "وبه كان يعد أيوب بن المتوكل ويعقوب بن إسحاق الحضرمي غير أن أيوب خالف عاصماً في آية واحدة وهي قوله عز وجل في سورة ص (38) (38) لم يعدها عاصم وعدها أيوب تابع فيها الكوفيين. وقد قيل إنَّ عاصماً كان يعدها، وأن أيوب كان يسقطها والأول عندنا أصح"(al-Dani 1994) .ونقل هذا القول عبد الرازق علي إبراهيم (1988) في كتابه المحرر الوجيز. 
وخلاصة القول، فمن هذه المعلومات المسرودة آنفاً، يمكن الملاحظة أن ما قرره علماء العدد والقراءات في اعتبار مذاهب العدد للقراءات المتواترة أسبابه تعود إلى عدة أمور: كون الإمام الذي تنسب إليه القراءة راوياً

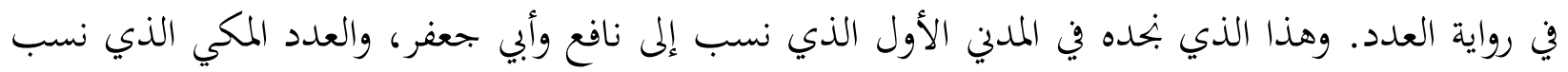
إلى عبد الله ابن كثير، والعدد الدمشقي الذي نسب إلى عبد الله بن ابن عامر، والعدد الكوفي الذي نسب إلى والى لهدي

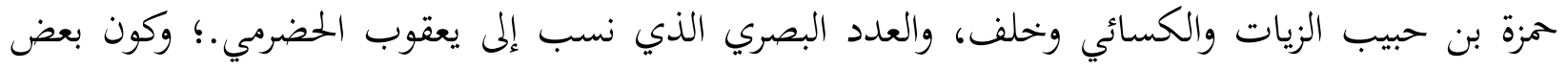
الرواة الذين رووا العددشيخً الإمامالذي تنسب إليه القراءة. وهذا الذي بنحه في قراءة أبي عمرو البصري التي اعتبرها بعض العلماءعدد المدني الأول لعرضه على شيخه أبي جعفر المدني؛ وكون بعض الرواة الذين رووا العدد تلاميذ الإمام الذينتنسب إليه القراءة. وهذا ما ندركه في قراءة نافع التي اعتبرها بعض العلماء عدد المدني الأخير لأغها مروية عن بعض تلاميذه، وهم: إسماعيل بن جعفر، وسليمان بن جماز، وعيسى بن مينا قالون؛ وكون

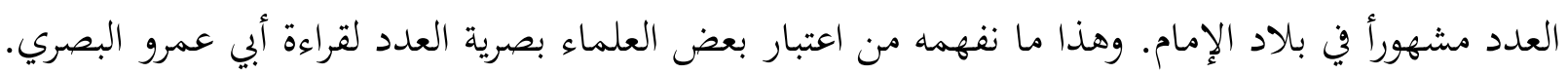

\section{المصاحف القرآنية المطبوعة والعدد المعول فيها}

وقد اختار الباحثون -ما بوسعهم- عدداً من المصاحف القرآنية التي تطبع على روايات متواترة مختلفة في بعض الدول الإسلامية، لتكون نموذجاً في تحقيق أهداف هذا البحث، لمعرفة مدى تطبيق هذا الخلاف في طباعة المصاحف القرآنية على اختلاف رواياتا المتواترة في العالم. وإليكم تلك المصاحف مع بيان العدد المعتمد في طبعها، وقسمها الباحثون حسب الروايات التي طبعت المصاحف بها: أ- مصحف مطبوع على رواية قالون عن نافع. المصحاف التي طبعت على هذه الرواية الذي بين يدي الباحثين ثلاث نسخ، وهي: • المصحف الذي طبعه بحمع الملك فهد لطباعة المصحف الشريف بالمدينة المنورة: واعتمد هذا المصحف على مذهب المدني الأخير في عد آياته. 
• المصحف الذي طبعته دار الفضيل ببنغازي ليبيا:اعتمد هذا المصحف على ما هو معدود بالمصحف

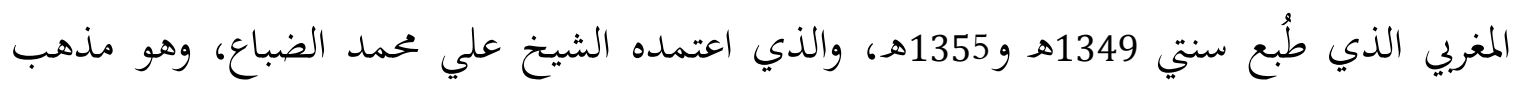
المدني الأخير.

المصحف الذي طبعه دار المعرفة بدمشق:اختلف هذا المصحف عن سابقَيْهِ حيث التزم بالمدني الأول في عدّ آيات في طباعة مصحفهم. ومرجع هذا الخلاف هو اختلاف اللجنة العلمية التي أشرفت على طباعة هذه المصاحف في اعتبار مذهب العدد لنافع، فذهب بعضهم إلى أها المدني الأخير، وهو قولالمالقي وابن الجزري، والصفاقسي والضباع والقاضي. وذهب آخرون إلى أنه المدني الأول، وهو قول الداني والجعبري، كما بيَّنا سابقاً. ب- مصحف مطبوع على رواية ورش عن نافع. المصحاف المطبوعة على رواية ورش عن نافع التيبين يدي الباحثينخمس نسخ، وهي:

• المصحف الذي طبعه بجمع الملك فهد لطباعة المصحف الشريف بالمدينة المنورة:اعتمد هذا المصحف على مذهب المدني الأخير في عد آياته، كما اعتمد في طباعة مصحف قالون عن نافع، ولم يفرق البحمع بين روايتَيْ قراءة نافع. • المصحف الذي طبع في المملكة المغربية: وأشير في ذيل المصحف، أنه اتبع مذهب المدني الأخير-كما ذهب إليه مصحف المدينة النبوية -أي المصحف الذي طبعه بجمع الملك فهد لطباعة المصحف بلف الشريف- في عد آياته.

المصحف الذي طبعته دار المعرفة بدمشق: وخالف هذا المصحف ما قرره علماء العدد في اعتبار مذهب العدد لورش، حيث إنه لم يعتبره المدني الأخير ولا الأول، بل اعتمد على العدد الكوفي في عد المداء

المصحف الذي طبعته مؤسسة الطباعة الشعبية للجيش بالجزائر: وأشير في هامش المصحف إلى أنه اتبع مذهب الكوفي، وذكر أيضاً أن هذا القرار ما ذهب إليه الشيخ عامر السيد عثمان ونخبة من المشايخ المغاربة. • المصحف الذي طبعته مؤسسة الوطنية للفنون المطبعية بالجزائر: وأشير في التعريف بالمصحف الذي وضعه الشيخ عامر السيد عثمان، أنه اتبع مذهب الكويخ في عد آياته. 
ت- مصحف مطبوع على رو/ية الدوري عن أبي عمرو. قد تمكن الباحثون من الاطلاع على نسختين من المصاحف التي طبعت على رواية الدوري عن أبي عمرو، وهما:

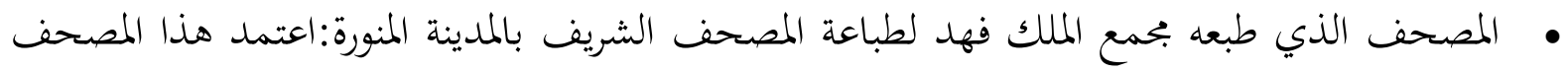

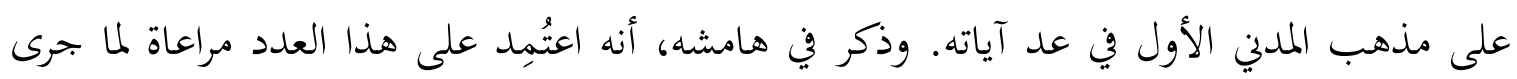
عليه العدد في السودان، حيث إفم يعدون الآي بعدد المدني الأول، الذي يروى عن أهل الهي البصرة.

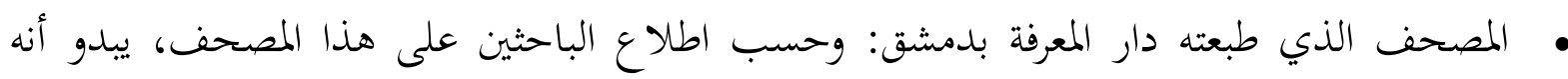

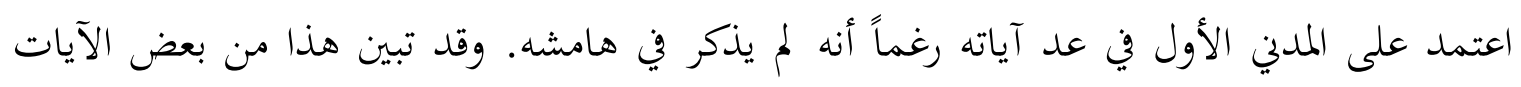

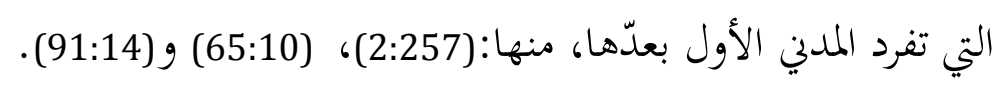

ث- مصحف مطبوع على رواية حفص عن عاصم. يعتبر هذا المصحف أكثره انتشاراً في العالم لقراءة عامة

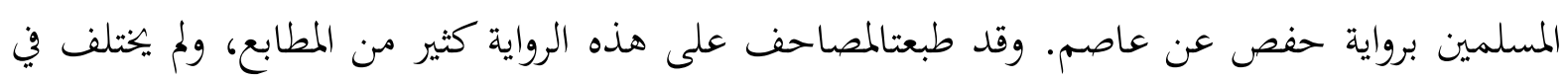

$$
\text { اعتبار مذهب العدد لها وهو العدد الكوفي. }
$$

ج-مصحف مطبوع على رواية شعبة عن عاصم. قد تمكن الباحثون من الخصول على نسخة من هذا

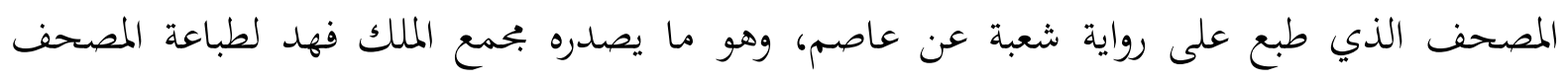
الشريف بالمدينة المنورة، واتبع في عد آياته طريقة الكوفيين.

ح-مصحف مطبوع على رواية خحف عن حمزة. لم يكن عند الباحثين نسخة المصحف المطبوع بهذه الرواية

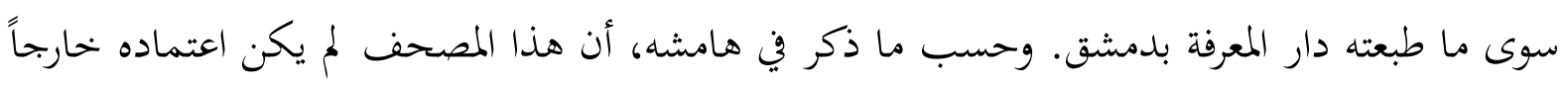

$$
\text { من العدد الكوفي في عد آياته. }
$$

وبعد اطلاعنا على هذه المصاحف المطبوعة وما اعتمد عليها في عد آياتما، يمكن الملاحظة أن أغلبية

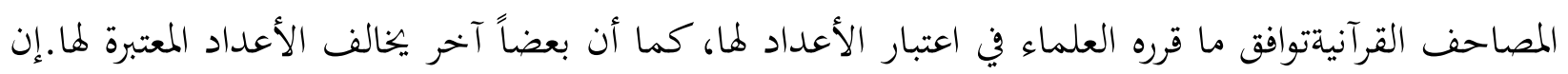
علماء العدد والقراءات اتفقوا في اعتبار الأعداد لبعض القراءات، كما أفم الختلفوا في البعض الغض الآخر. فالقراءات التي اتفق عليها العلماء في اعتبار الأعداد لها، هي: قراءة ابن كثير المكي، وابن عامر الشامي، وقراءة الشياء

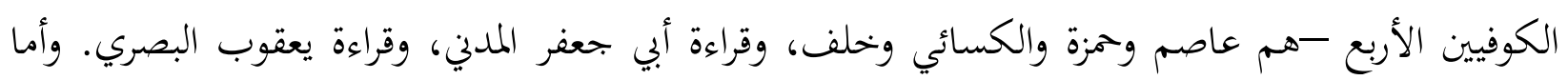

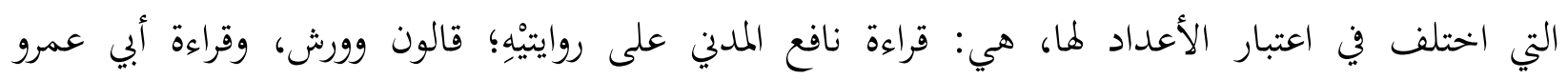


البصري.فالذي توصلت إليه هذه الدراسة من هذه الأقوال، يخطئ القول بإن القراءات المتواترة، ورواياتا تعتمد تماماً على العدد المشهور لبلداها في عد آياها.

وبعد التأمل في أسانيد هذه الأعداد، اكتشفت الدراسة على أن هذا التعيين والاعتبار -اتفاقاً أو

اختلافاً- عائدإلى أربعة أسباب، وهي: كون الإمام التي تنسب إليه القراءة راوياً في رواية العدد، أو كون بعض الرواة الذين رووالعدد شيخَ الإمام الذي تنسب إليه القراءة، أو كون بعض الرواة الذين رووا العدد تلاميذَالإمام الذي تنسب إليه القراءة، أو كون العدد مشهورأ في بلاد الإمام.

وين قضية طباعة المصاحف القرآنية على اختلاف الروايات المتواترة، توصلت الدراسة إلأن معظم هذه

المصاحف المطبوعة وافقت على ما قرره علماء هذا الفن في اعتبار مذهب العدد، كما أن بعضها لم يكن موافقاً بهذا القرار، وهو مصحف رواية ورش عن نافع الذي طبعته دار المعرفة بدمشق، ومؤسسة الطباعة الشعبية للجيش بالجزائر، والمؤسسة الوطنية للفنون المطبعية بالجزائر. فكل هذه المصاحف المذكورة خالفت ما قرره علماء العدد في اعتبار مذهب العدد لورث، حيث إنه لم يعتبره المدلي الأخير ولا الأول، بل اعتمد على العدد الكوفي في عد آياته. فعدم موافقة طباعة هذه المصاحف القرآنية لما قره العلماء وعدوهلا عنه -مع احترامنا للجنة العلمية المشرفة على تلك المصاحف - جدير بالبحث ويحتاج إلى تفصيل وتدقيق، خاصة لمعرفة سبب اختيار هذه اللجنة العدد الكوفي لرواية ورش، فضلاً عن المدين الأول أو الأخير الذي قررها العلماء لها.

\section{References}

Al-Qur'an al-Karim Riwayah Shu'bah `an `Asim. 1430H. Madinah Munawwarah: Mujamma`al-Malik Fahd li Tiba'ah al-Mushaf al-Sharif.

Al-Qur'an al-Karim Riwayah Warsh 'an Nafi`. 1426H. Madinah Munawwarah: Mujamma' al-Malik Fahd li Tiba`ah al-Mushaf al-Sharif.

Al-Qur'an al-Karim Riwayah Qalun 'an Nafi`. 1427H. Madinah Munawwarah: Mujamma`al-Malik Fahd li Tiba`ah al-Mushaf al-Sharif.

Al-Qur'an al-Karim Riwayah Qalun 'an Nafi'. 2012. Benghazi: Dar al-Fudhail.

Al-Qur'an al-Karim Riwayah Qalun 'an Nafi’. 1427H. Damascus: Dar al-Ma`rifah.

Al-Qur'an al-Karim Riwayah Warsh 'an Nafi'.1430H. Damascus: Dar al-Ma`rifah.

Al-Qur'an al-Karim Riwayah Khalaf 'an Hamzah. 1428H. Damascus: Dar al-Ma`rifah.

Al-Qur'an al-Karim Riwayah Warsh 'an Nafi`. n.d. al-Jazair: Muassasah al-Tiba`ah al-Sha`biyyah li alJaysh.

Al-Qur'an al-Karim Riwayah Warsh 'an Nafi'. 2013. Al-Jaza'ir: Muassasah al-Wataniyyah li al-Funun al-Matba iyyah.

Al-Qur'an al-Karim Riwayah Warsh 'an Nafi'. n.d. al-Mamlakah al-Maghribiyyah: Wizarah al-Awqaf wa al-Shu'un al-Islamiyyah. 
قضية في طباعة المصاحف القرآنية: الخلاف في علم العلد وتطبيقه في طباعة المصاحف القرآنية في العالم

Abd Muhaimin Ahmad et al.

Ahmad Khalid Shukri. 2012. Al-Muyassar fi 'Ilm `Addi Ayi al-Qur'an. Jeddah: Ma`had al-Imam alShatibi.

Ahmad Muhammad Muflih al-Qudah et al. 2009. Muqaddimat fi 'Ilmi al-Qira'at. 'Amman: Dar 'Ammar.

`Abd al-Raziq `Ali Ibrahim. 1988. Al-Muharrar al-Wajiz fi `Addi Ayi al-Kitab al-'Aziz. Riyadh: Maktabah al-Ma'arif.

`Abd al-Raziq `Ali Ibrahim. 1989. Murshid al-Khillan ila Ma'rifah 'Addi Ayi al-Qur'an. Beirut: alMaktabah al-'Asriyyah.

al-Dani, 'Uthman bin Sa`id. 1994. Al-Bayan fi `Addi Ayi al-Qur'an. Kuwait: Markaz al-Makhtutat wa al-Turath wa al-Watha'iq.

al-Dimyati, Ahmad bin Muhammad. 2006. Ithaf Fudala' al-Bashar fi al-Qira'at al-Arba 'ah 'Ashar. Beirut: Dar al-Kutub al-'Ilmiyyah.

al-Haddad, Muhammad bin `Ali. 1924. Sa'adah al-Darain fi Bayan wa `Addi Ayi Mu jiz al-Thaqalain. Egypt: Matba`ah al-Ma`ahid.

al-Huzali, Yusuf bin `Ali. 2007. Al-Kamil fi al-Qira'at al-Asyar wa al-Arbai ìn al-Za'idah `Alaiha. Cairo: Muassasah Sama.

Ibn al-Jazari, Muhammad bin Muhammad. 2006. Al-Nashr fi al-Qira'at al-'Asyar. Beirut: Dar al-Kutub al-'Ilmiyyah

Ibn Mahran, Ahmad bin al-Husin. 2004. Al-Mabsut fi al-Qira'at al- 'Ashar. Tanta: Dar al-Sahabah li alTurath.

Ibn Manzur, Muhammad bin Mukrim. 2005. Lisan al-'Arab. Beirut: Dar Sadir.

al-Ja`bari, Ibrahim bin `Umar. 2005. Husnu al-Madad fi Fan al-`Adad. Al-Haram: Maktabah Awlad alSheikh li al-Turath.

al-Maliqi, `Abd al-Wahid bin Muhammad. 2003. Al-Dur al-Nathir Sharh Kitab al-Taysir. Beirut: Dar al-Kutub al-'Ilmiyyah.

al-Mukhallilati, Ridhwan bin Muhammad. 1992. Al-Qawl al-Wajiz fi Fawasil al-Kitab al-'Aziz. Madinah Munawwarah: n.p.

al-Mutawalli, Muhammad Ahmad. n.d. Tahqiq al-Bayan fi 'Addi Ayi al-Qur'an. n.p.: n.p.

al-Nuwairi, Muhammad bin Muhammad. 2009. Sharh Tayyibah al-Nashr fi al-Qira'at al-'Ashar. Beirut: Dar al-Kutub al-'Ilmiyyah.

al-Qadi, `Abd al-Fattah `Abd al-Ghani. 1982. Al-Budur al-Zahirah fi al-Qira'at al-Mutawatirah min Tariq al-Shatibiyyah wa al-Durrah. Beirut: Dar al-Kutub al-'Arabi.

al-Qadi, `Abd al-Fattah `Abd al-Ghani. 1983. Nafais al-Bayan Sharh al-Faraid al-Hisan. Madinah Munawwarah : Maktabah al-Dar.

al-Qadi, `Abd al-Fattah `Abd al-Ghani. 2008. Bashir al-Yusr Sharh Nazimah al-Zuhr. Beirut: Dar alSalam.

al-Sakhawi, 'Ali bin Muhammad. 1997. Jamal al-Qurra' wa Kamal al-Iqra'. Beirut: Muassasah alKutub al-Thaqafiyyah.

al-Safaqasi, `Ali bin Muhammad. 1999. Ghaith al-Naf fi al-Qira'at al-Sab`. Beirut: Dar al-Kutub al'Ilmiyyah. 